NASA TECHNICAL MEMORANDUM

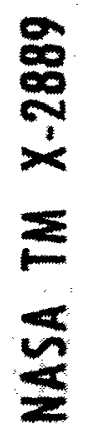

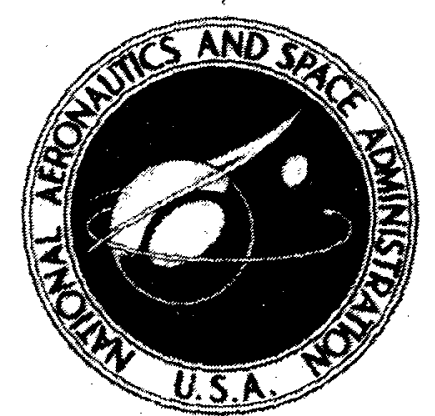

N75-3050g

NASA TM X-2889

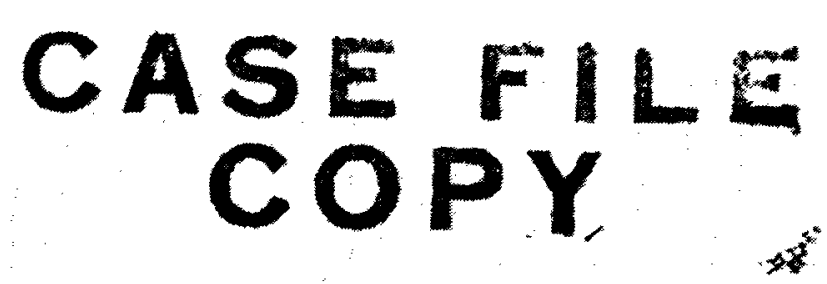

OBSERVATION OF OXIDE PARTICLES

BELOW THE APPARENT OXYGEN

SOLUBILITY LIMIT IN TANTALUM

by Stephan Stecura

Lewis Research Center

Cleveland, Obio 44135

national aeronautics and space administration - washington, D. C. - September 1973 


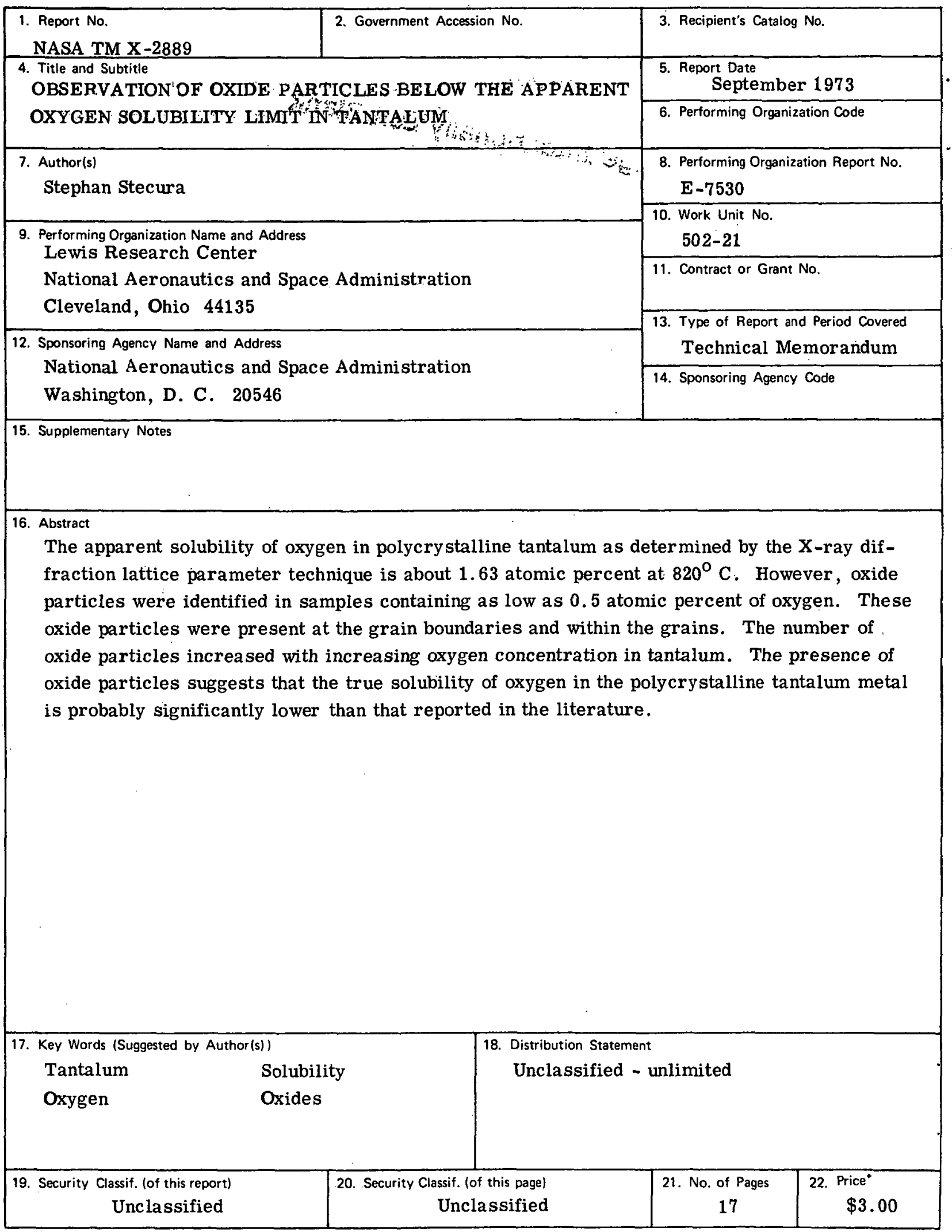

${ }^{*}$ For sale by the National Technical Information Service, Springfield, Virginia 22151 


\title{
OBSERVATION OF OXIDE PARTICLES BELOW THE APPARENT

\author{
OXYGEN SOLUB ILITY LIMIT IN TANTALUM
}

\author{
by Stephan Stecura
}

Lewis Research Center

\section{SUMMARY}

The distribution of oxygen in high purity polycrystalline tantalum containing up to 3.0 atomic percent of oxygen was studied by $\mathrm{X}$-ray diffraction, microhardness mea surements, extraction in methanol-bromine solution, polarized light optical microscopy, and electron microscopy .

$\mathrm{X}$-ray diffraction and microhardness measurements indicated a uniform oxygen distribution in all oxygen-doped samples. From the $\mathrm{X}$-ray diffraction lattice parameter study, it was concluded that the apparent solubility of oxygen in polycrystalline tantalum at $820^{\circ} \mathrm{C}$ is about 1.63 atomic percent. Neither method disclosed the presence of tantalum oxides on the surface or in the matrix of the tantalum metal.

How ever, tantalum oxides were extracted from the samples containing less than 1.63 atomic percent oxygen. The extracted oxides were identified by X-ray diffraction as $\mathrm{Ta}_{6} \mathrm{O}, \mathrm{Ta}_{4} \mathrm{O}, \mathrm{Ta}_{2} \mathrm{O}, \mathrm{TaO}_{2}$, and $\mathrm{Ta}_{2} \mathrm{O}_{5}$. Particles assumed to be oxides were seen by electron microscopy in the samples containing about 0.5 atomic percent oxygen. Electron microscopy investigations further indicated that these particles were present at the grain boundaries and within the grains. Furthermore, investigations by polarized light optical microscopy indicated that the number of particles in tantalum increases with the increase of oxygen concentration in tantalum.

The presence of tantalum oxides below the oxygen solubility limits reported in the literature and determined in this study suggests that the true solubility of oxygen in the polycrystalline tantalum metal may be significantly lower than reported in the literature. Segregation of oxygen at the grain boundaries is believed to be primarily responsible for. the observed behavior. The determination of the solubility of oxygen in the tantalum metal might be determined by the $\mathrm{X}$-ray diffraction technique provided that the amount of oxygen combined in the form of oxides can be determined. 


\section{INTRODUCTION}

The presence of oxygen in tantalum affects many of its properties. Thus the uses of tantalum may be limited or enhanced by the presence of dissolved oxygen. One case where the usefulness of the tantalum is detrimentally affected by oxygen is in hightemperature heat pipes. Tantalum has been used for heat pipes up to $1600^{\circ} \mathrm{C}$ with lithium as a working fluid. It has been reported that these heat pipes failed at high temperatures, the failures being attributed to the presence of oxygen in the tantalum (refs. 1 and 2). Tantalum has also been used to contain gettering agents such as yttrium in lithium in the T-111 tantalum alloy (Ta $8 \mathrm{wt}$. \% W - $2 \mathrm{wt}$. \% Hf) heat pipes.

A review of the literature showed that the reported solubility values for oxygen in tantalum vary. For example, the solubility of oxygen at $820^{\circ} \mathrm{C}$ has been reported at 2.8 atomic percent (ref. 3), 1.9 atomic percent (ref. 4), and 1.0 atomic percent (ref. 5). It is possible that these differences might be due to the presence of tantalum suboxides and/or oxides at these low oxygen concentrations. The presence of these suboxides or oxides would not be detected by the methods used in determining the oxygen solubility in polycrystalline tantalum if these oxides are present as widely dispersed, small particles. If such oxides are present in tantalum, they would affect not only the compatibility of tantalum with other metals but also such properties as ductility and electrical and thermal conductivities.

As part of a larger study involving lithium corrosion of oxygen-doped tantalum, the distribution of oxygen in tantalum was examined. This study discusses the distribution of oxygen in tantalum at $820^{\circ} \mathrm{C}$. The data were obtained by X-ray diffraction, microhardness measurements, extraction in methanol-bromine solution, electron microscopy, and polarized light optical microscopy.

\section{MATERIALS, APPARATUS, AND PROCEDURE}

The data in this study were obtained as follows. High purity tantalum cups and coupons were doped with high purity oxygen to various oxygen concentration levels. These samples were then examined by chemical analyses, X-ray diffraction analyses, microhardness measurements, extraction in the methanol-bromine solutions, electron microscopy, and polarized light optical microscopy.

\section{Materials}

Tantalum cups were machined from high purity, 1.27-centimeter-diameter, polycrystalline tantalum rod and coupons from high-purity polycrystalline tantalum sheet. 
Cups and coupons were cleaned in the manner described in reference 6 . After cleaning, both cups and coupons were annealed at $1200^{\circ} \mathrm{C}$ for 2 hours at $10^{-8}$ torr pressure. Two randomly selected cups and four coupons were submitted for analyses of impurities. As indicated in table I, maximum total impurities in the tantalum metal were less than 0.05 weight percent. Oxygen, nitrogen, carbon, and hydrogen were determined by inert-gas fusion, modified Kjeldahl (ref. 7), combustion, and hydrogen extraction methods, respectively. Metallic impurities were determined by either mass or optical spectrographic methods. The original oxygen concentrations in the cups and coupons were about 12 and 50 weight ppm, respectively. Annealed cups and coupons were doped with oxygen to various oxygen concentration levels. After doping, some of the oxygen-doped cups and coupons were annealed at $1200^{\circ} \mathrm{C}$ for 2 hours then cooled to about $820^{\circ} \mathrm{C}$ and annealed at this temperature for 3 hours. The dimensions of the cups and coupons used in this study are given in figure 1.

The oxygen gas used in the doping experiments had the following impurities in parts per million by weight: nitrogen, 5; argon, $<1$; krypton, 8; xenon, $<1$; nitrous oxide $\left(\mathrm{N}_{2} \mathrm{O}\right),<1$; and water, $<1$.

\section{Apparatus}

The doping of tantalum cups and coupons was done in an apparatus described by Barrett (ref. 8). Normally, four cups or four coupons were doped at one time to a particular oxygen concentration level. The estimated accuracy of temperature measurement in this resistance heated quartz tube furnace was $\pm 10^{\circ}$ at $820^{\circ} \mathrm{C}$.

\section{Procedure}

Tantalum cups or coupons were hung by platinum wires on a quartz sample holder and placed into the furnace. The furnace was evacuated to about $10^{-7}$ torr pressure and then slowly heated to $820^{\circ} \mathrm{C}$. During heat up, the pressure in the furnace did not exceed $5 \times 10^{-6}$ torr. After 1 hour at this temperature, oxygen was introduced into the furnace. All doping runs were conducted at $2 \times 10^{-4}$ to $3 \times 10^{-4}$ torr oxygen pressure.

After completing the doping experiments, half of the samples were annealed at $1200^{\circ} \mathrm{C}$ for 2 hours at $10^{-8}$ torr pressure followed by annealing at $820^{\circ} \mathrm{C}$ for 3 hours. The rest of the samples were evaluated in the as-doped condition. Afterward, some of the samples were subjected to X-ray diffraction analyses, microhardness measurements, extraction in methanol-bromine solution, electron microscopy, and polarized light optical microscopy . 


\section{RESULTS AND DISCUSSION}

To determine the presence of oxides in tantalum, samples were doped at $820^{\circ} \mathrm{C}$ to various oxygen concentration levels. The oxygen concentration levels varied between 0.02 atomic percent of oxygen in as-received tantalum to about 3.0 atomic percent. The oxygen concentrations were determined both by weighing the samples before and after doping with oxygen and by inert gas fusion analysis. The differences between the oxygen concentrations as determined by the two methods were negligible (table II). The data in table II also show that the carbon concentrations did not change with the increase in the oxygen concentration in the samples. However, the nitrogen concentrations in the samples increased slightly with the increase in oxygen concentrations.

The X-ray diffraction data confirmed that no oxide layers were formed on the surfaces of any of the samples. Complete $X$-ray diffraction patterns obtained of the oxygendoped sample surfaces showed that only tantalum $X$-ray diffraction peaks were present. The calculated lattice parameter values for 211, 310, and 321 Miller indices showed about the same increase due to increase of oxygen concentration in the tantalum. This then indicates that there was no preferential distribution of oxygen in the tantalum lattice.

The X-ray data in figure 2 show a break in the lattice parameter against oxygen content curve at about 1.63 atomic percent of oxygen. This value should be the solubility value for oxygen in tantalum at $820^{\circ} \mathrm{C}$. The 1.63 atomic percent value is in very good agreement with the solubility data reported by Gebhard (ref. 4), but is in disagreement with the solubility values reported in references 3 and 5 (fig. 3). The data in fig-: ure 2 also show that the annealing of oxygen-doped samples at $820^{\circ} \mathrm{C}$ had no significant effect on the lattice parameter values, indicating that an equilibrium condition in the samples was established during doping with oxygen.

From the data in figure 2 it can be concluded that tantalum suboxides and/or oxides should have been formed above 1.63 atomic percent oxygen level. However, no such oxides were detected by the $\mathrm{X}$-ray diffraction technique. This could be due to the small amount of oxide phase present. Since the presence of oxides above 1.63 atomic percent of oxygen was not detected, it is also possible that tantalum oxides might have been formed below this value but were not detected. This implies that the true solubility of oxygen in tantalum could be lower than reported in references 3 to 5 and determined in this study.

The absence of tantalum oxides in these oxygen-doped samples is also inferred from the microhardness data (fig. 4). Microhardness measurements were used by Kofstad (ref. 9) in support of X-ray diffraction to establish a uniform distribution of oxygen in tantalum. Brehm (ref. 10) used microhardness measurements to determine the distribution and concentration of oxygen in niobium. The microhardness was observed in this study to increase linearly with the increase in oxygen concentration (fig. 4). These data 
are about the same as those reported in reference 11. This linearity is observed even in samples in which the oxygen concentrations have exceeded the apparent solubility limit. Furthermore, it was found that annealing samples at about $820^{\circ} \mathrm{C}$ for 3 hours at $10^{-8}$ torr pressure had no significant effect on the microhardness of oxygen-doped tantalum. The X-ray diffraction and microhardness data indicate that the oxygen was probably distributed uniformily since no oxides were detected. However, the fact that no oxides were detected at concentrations above the solubility limit of oxygen in tantalum suggests that the oxides were present in very small amounts and as very small particles.

To resolve this problem it was decided to extract the oxides, if they were present, in a methanol-bromine solution and also to study these oxygen-doped samples by electron microscopy and polarized light optical microscopy. Six tantalum samples containing about $0.02,0.5,0.7,1.2,1.4$, and 1.9 atomic percent oxygen were dissolved in methanol - 15-volume-percent bromine solutions. No residue was observed from the sample containing 0.02 atomic percent oxygen. Although residues were observed from the samples containing 0.5 and 0.7 atomic percent oxygen, the amounts of residues were insufficient for $\mathrm{X}$-ray difraction analysis. : Sufficient amounts of residues were recovered from the remaining three samples. The amount of residue was greater for the sample containing 1.9 atomic percent oxygen than for the samples containing 1.4 and 1.2 atomic percent oxygen.

The results of optical spectrographic analyses of the 1.2,1.4, and 1.9 atomic percent oxygen sample residues showed that the residues contained tantalum. The recovered residues were identified by $X$-ray diffraction analyses on the basis of the $X$-ray diffraction data reported in references 12 to 16 . The suboxides and oxides found in these residues were $\mathrm{Ta}_{6} \mathrm{O}, \mathrm{Ta}_{4} \mathrm{O}, \mathrm{Ta}_{2} \mathrm{O}, \mathrm{TaO}_{2}$, and $\mathrm{Ta}_{2} \mathrm{O}_{5}$. The X-ray diffraction data for 1.4 and 1.9 atomic percent oxygen sample residues are given in table III. The $\mathrm{X}$-ray diffraction data for the 1.2 atomic percent oxygen sample residue were similar to those from the 1.4 atomic percent oxygen sample residue. The data in table III also show that only the strongest $\mathrm{X}$-ray diffraction peaks for various tantalum oxides were observed.

The recovery of these oxides from samples containing,less than 1.63 atomic percent oxygen suggests that the true solubility in tantalum at $820^{\circ} \mathrm{C}$ is less than 1.63 atomic percent. Furthermore, the recovery of these oxides points out that the usefulness of the $\mathrm{X}$-ray diffraction technique in determining the true solubility of oxygen in the polycrystalline tantalum is very limited.

The presence of oxides below 1.63 atomic percent of oxygen is also supported by electron and optical microscopy observations. The four samples investigated contained $0.02,0.5,0.92$, and 1.9 atomic percent of oxygen, respectively. Particles were observed by electron microscopy in all samples and are believed to be tantalum oxides, based on the identification of oxides in the extracted residues. In the tantalum sample containing 0.02 atomic percent of oxygen, only one small particle was found after a very 
extensive and careful investigation of most of this sample. Many particles were found in the sample containing 0.5 atomic percent of oxygen. The number of particles increased with the increase of the oxygen concentration in tantalum. Optical microscopy observations gave similar results as is apparent from the photomicrographs shown in figures 5 to 7 . These photomicrographs were obtained by polarized light optical microscopy. The photomicrograph of the sample containing 0.02 atomic percent of oxygen shows no second phase (fig. 5). The photomicrograph (fig. 6) of the 0.5 atomic percent oxygen sample shows second phase, represented by the white dots in the photomicrograph. The number of white dots is even greater in the photomicrograph of the sample containing 1.9 atomic percent of oxygen (fig. 7). Thus, the polarized light optical microscopy observations confirm that the number of particles increases with the increase of oxygen concentration in tantalum.

The electron microscopy investigation also indicated that in the sample containing 0.50 atomic percent oxygen, most of the oxide particles were present at the grain boundaries. Only a few particles were found within the grains. All of these particles were similar to the particles shown in figure 8. Similar oxide particles were observed in the samples.containing 0.92 and 1.9 atomic percent oxygen. It was observed that as the oxygen concentration increased the number of oxide particles within the grains increased. Furthermore, larger particles were observed with increasing oxygen concentration. This is readily apparent from a comparison of the particles shown in figure 8 with those shown in figures 9 and 10 .

The presence of oxide particles in the tantalum sample containing about 0.50 atomic percent of oxygen suggests that the true solubility of oxygen in tantalum metal at $820^{\circ} \mathrm{C}$ is significantly lower than indicated by the lattice parameter measurements in this study and reported in references 3 to 5 . Indeed, it might be concluded that the true solubility of oxygen in polycrystalline tantalum at all temperatures is significantly lower than reported in references 3 to 5 .

The extraction of oxides, electron microscopy, and polarized light optical microscopy investigations suggest that it would be very difficult to determine the true solubility, distribution, and concentration of oxygen in polycrystalline tantalum by X-ray diffraction and microhardness measurements. Both of these methods have been previously used for such purposes (refs. 3, 4, 9, 10, 17, and 18). The X-ray diffraction method could be used to determine the true solubility of oxygen in polycrystalline tantalum provided a method is found for determining quantitatively the amount of oxygen in the form of oxides. The use of single crystals would eliminate grain boundaries and should make it possible to obtain oxygen solubility values that would be closer to the true solubility values. 


\section{CONCLUSIONS}

High purity polycrystalline tantalum samples were doped with oxygen at $820^{\circ} \mathrm{C}$ up to 3.0 atomic percent level. These samples were studied by X-ray diffraction, microhardness measurements, extraction in methanol-bromine solution, electron microscopy, and polarized light optical microscopy.

It was determined that the apparent solubility of oxygen in polycrystalline tantalum at $820^{\circ} \mathrm{C}$ is about 1.63 atomic percent, which is in good agreement with the values reported in the literature. However, this is not the true solubility of oxygen in tantalum because tantalum oxide particles were found at oxygen concentrations as low as 0.5 atomic percent. Segregation of oxygen to grain boundaries is believed to be primarily responsible for the observed behavior. The true lattice solubility of oxygen in tantalum is significantly lower than that reported in the literature and probably cannot be determined by using polycrystalline samples.

The formation of small oxide particles at the grain boundaries and within the grains limits the usefulness of the X-ray diffraction technique in determining the true solubility of oxygen in polycrystalline metals.

Lewis Research Center,

National Aeronautics and Space Administration,

Cleveland, Ohio, June 20, 1973,

502-21.

\section{REFERENCES}

1. Busse, C. A.; Geiger, F.; and Strub, H.: High Temperature Lithium Heat Pipes. Proceedings of Second.International Conference on Thermionic Electrical Power Generation. Euratom, Luxembourg, 1969, pp. 495-506.

2. Busse, C. A.: Korrosion in Hochtemperatur-Lithium-Wärmerohren mit Niob1 Zirkon oder Tantal als Wandmaterial. Corrosion Sci., vol. 10, no. 2, 1970, pp. 65-84.

3. Vaughan, Dale A.; Stewart, Oliver M. : and Schwartz, Charles M.: Determination of Interstitial Solid-Solubility Limit in Tantalum and Identification of the Precipitate Phases. Trans. AIME, vol. 221, no. 5, Oct. 1961, pp. 937-946.

4. Gebhardt, Erich; and Seghezzi, Hans-Dieter: Untersuchungen in System TantalSauerstoff. II. Reaktionen und Gleichgewichte zwischen Mischkristall-und

Oxydphasen. Zeit. f. Metallkunde, vol. 50, no. 9, 1959, pp. 521-527. 
5. Parkman, M.; Pape, R.; McRae, R.; Brayton, D.; and Reed, L. : Solubility and Diffusion of Oxygen in Tantalum. NASA CR-1276, 1969.

6. Stecura, Stephan: Apparent Solubilities of Commercially Pure and Oxygen-Doped Tantalum and Niobium in Liquid Potassium. NASA TN D-5875, 1970.

7. Kallman, Silve; Hobart, Everett W.: Oberthin, Hans K.; and Brienza, Walter C., Jr . : Determination of Traces of Nitrogen in Refractory Metals and Alloys by Hydrofluoric Acid - Phosphoric Acid - Potassium Dichromate Decomposition and Indophenol Photometry. Anal. Chem., vol. 40, no. 2. Feb. 1968, pp. 332-335.

8. Barrett, Charles A.: Controlled Oxygen Additions to Refractory Metals. NASA TM $\mathrm{X}-1799,1969$.

9. Kofstad, P.: Low-Pressure Oxidation of Tantalum at $1300^{\circ}-1800^{\circ} \mathrm{C}$. J. LessCommon Metals, vol. 7, 1964, pp. 241-266.

10. Brehm, William F.: Grain Boundary Penetration of Niobium by Lithium. Rep. 735, Material Sci. Center, Cornell Univ. (A EC Rep. NYU-3228-11), 1967.

11. Shtremel, M. A.; Volkov, A. K.; and Anuchkyn, A. M.: Prochnost Tverdykh Rastvorov Tantal-Kyslorod (Microhardness of Tantalum-Oxygen Solid-Solution). Akad. Nauk SSSR, Izv., Metally, no. 2, Mar.-Apr. 1972, pp. 169-175.

12. Brauer, G.; Müller, Horst; und Kühner, G.: Oxide der Tieftemperaturoxydation von Niob und Tantal. J. Less-Common Metals, vol. 4, no. 6, Dec. 1962, pp. 533-546.

13. Lehovec, $\mathrm{K}$ : Lattice Structure of $\beta-\mathrm{Ta}_{2} \mathrm{O}_{5}$. J. Less-Common Metals, vol. 7, no. 6, Dec. 1964, pp. 397-410.

14. Schönberg, Nils: An X-ray Investigation of Tantalum-Oxygen System. Acta Chem. Scand. , vol. 8, 1954, pp. 240-245.

15. Steeb, S.; and Renner, J.: Ermittlung der Struktur des Tantalsuboxydes $\mathrm{TaO}_{\mathrm{z}}$ $\left(\mathrm{Ta}_{2} \mathrm{O}\right)$ Mittels Elektronenbeugung. J. Less-Common Metals, vol. 9, 1965, pp. 181-189.

16. Zaslavskyj, A. I. ; Zvynchuk, R. A.: and Tutov, A. G.: Rentgenograficheskoe Issledovanie Polymorfoza $\mathrm{Ta}_{2} \mathrm{O}_{5}$ (X-Ray Diffraction Investigation of Polymorphism in $\mathrm{Ta}_{2} \mathrm{O}_{5}$ ). Doklady Akad. Nauk SSSR, Crystallog., vol. 104, no. 3, 1955, pp. $409-411$.

17. Seybolt, A. U. : Solid Solubility of Oxygen in Columbium. Trans. AIME, vol. 200, June 1954, pp: 774-776.

18. Elliot, Rodney P.: Columbium-Oxygen System. Trans. ASM, vol. 52, 1959, pp. 990-1014. 
TABLE I. - IMPURITY CONTENT OF TANTALUM SAMPLES

\begin{tabular}{|c|c|c|c|c|c|}
\hline \multirow[t]{2}{*}{ Impurity } & \multicolumn{2}{|c|}{$\begin{array}{l}\text { Concentration of impurity, } \\
\text { ppm by weight }\end{array}$} & \multirow[t]{2}{*}{ Impurity } & \multicolumn{2}{|c|}{$\begin{array}{c}\text { Concentration of impurity, } \\
\text { ppm by weight }\end{array}$} \\
\hline & Cup & Coupon & & Cup & Coupon \\
\hline Carbon $^{\mathrm{a}}$ & 5 & 22 & Lithium. & $<1$ & $<1$ \\
\hline Oxygen $^{a}$ & 15 & 50 & Magnesium & $<1$ & $<1$ \\
\hline Nitrogen ${ }^{a}$ & 22 & 18 & Manganese & $<1$ & $<1$ \\
\hline Hydrogen $^{\mathrm{a}}$ & 5 & 6 & Molybdenum & 10 & 15 \\
\hline Aluminum & $<1$ & $<1$ & Nickel & 20 & 20 \\
\hline Antimony & $<1$ & $<1$ & Niobium & 100 & 100 \\
\hline Arsenic & $<1$ & $<1$ & Osmium & $<1$ & $<1$ \\
\hline Barium & $<1$ & $<1$ & Palladium & $<1$ & $<1$ \\
\hline Berilium & $<1$ & $<1$ & Platinum & 10 & 10 \\
\hline Bismuth & $<1$ & $<1$ & Potassium & 10 & 10 \\
\hline Boron & $<1$ & $<1$ & Rhenium & --- & --- \\
\hline Bromine & $<1$ & $<1$ & Rhodium & $<1$ & $<1$ \\
\hline Cadmium & $<1$ & $<1$ & Rubidium & $<1$ & $<1$ \\
\hline Calcium & $<1$ & $<1$ & Ruthenium & $<1$ & $<1$ \\
\hline Cesium & $<1$ & $<1$ & Silicon & 5 & 10 \\
\hline Chlorine & 10 & 15 & Silver & $<1$ & $<1$ \\
\hline Chromium & 5 & 8 & Sodium & $<1$ & $<1$ \\
\hline Cobalt & $<1$ & $<1$ & Strontium & $<1$ & $<1$ \\
\hline Copper & 5 & 5 & Tantalum & High & High \\
\hline Fluorine & 5 & 5 & Tellurium & 1 & $<1$ \\
\hline Gallium & $<1$ & $<1$ & Thalium & $<1$ & $<1$ \\
\hline Germanium & $<1$ & $<1$ & Thorium & 50 & 50 \\
\hline Gold & 20 & 20 & Tin & $<1$ & $<1$ \\
\hline Hafnium & $<1$ & 5 & Titanium & 8 & 10 \\
\hline Indium & $<1$ & $<1$ & Tungsten $^{\mathbf{a}}$ & 4 & 5 \\
\hline Iodine & $<1$ & $<1$ & Vanadium & $<1$ & $<1$ \\
\hline Iridium & $<1$ & $<1$ & Zinc & 3 & 5 \\
\hline Iron & 20 & 30 & Zirconium & $<1$ & $<1$ \\
\hline Lead & $<1$ & $<1$ & & & \\
\hline
\end{tabular}

${ }^{\mathrm{a}}$ Results obtained by chemical analysis. All other data were obtained by optical spectrographic analyses. 
TABLE II. - OXYGEN, NITROGEN, AND CARBON

CONCENTRATIONS IN TANTALUM BEFORE

AND AFTER DOPING WITH OXYGEN

\begin{tabular}{|c|c|c|c|c|}
\hline \multirow{3}{*}{$\begin{array}{l}\text { Sample } \\
\text { number }\end{array}$} & \multicolumn{4}{|c|}{ Concentration, at. $\%$} \\
\hline & \multicolumn{2}{|c|}{ Oxygen } & \multirow[t]{2}{*}{ Nitrogen ${ }^{c}$} & \multirow[t]{2}{*}{ Carbon $^{d}$} \\
\hline & $\begin{array}{l}\text { By weight } \\
\text { difference }^{a}\end{array}$ & $\begin{array}{c}\text { By chemical } \\
\text { analysis }\end{array}$ & & \\
\hline $\mathrm{e}_{\mathrm{Ta}-1}$ & $--\infty$ & 0.020 & 0.028 & 0.008 \\
\hline $\mathrm{e}_{\mathrm{Ta}-2}$ & $-\cdots$ & .060 & .023 & .033 \\
\hline $\mathrm{Ta}-3$ & 0.188 & .202 & .045 & .029 \\
\hline $\mathrm{Ta}-4$ & .375 & .402 & $-\infty-$ & $\cdots$ \\
\hline Ta -5 & .438 & .462 & .072 & .024 \\
\hline Ta -6 & .738 & .774 &.--- & ---- \\
\hline Ta -7 & 1.406 & 1.446 & .079 & .018 \\
\hline Ta-8 & 2.398 & 2. 350 & .089 & .015 \\
\hline
\end{tabular}

${ }^{a}$ Determined by weighing the sample before and after the oxygen doping.

$\mathrm{b}_{\text {Deter mined by inert-gas fusion method. }}$

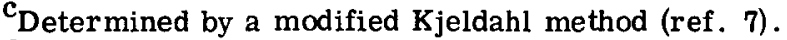

d Determined by combustion method.

$\mathbf{e}_{\text {Ta }-1}$ is an undoped crucible and Ta-2 is an undoped coupon. 
TABLE III. - X-RAY DIFFRACTION PATTERNS FOR THE RESIDUES

EXTRACTED FROM OXYGEN-DOPED TANTALUM

IN METHANOL-BROMINE SOLUTIONS

\begin{tabular}{|c|c|c|c|c|c|}
\hline \multicolumn{3}{|c|}{1.4 at. $\%$ oxygen } & \multicolumn{3}{|c|}{1.9 at. $\%$ oxygen } \\
\hline $\begin{array}{c}\text { d-spacing, } \\
m\end{array}$ & $\begin{array}{l}\text { Intensity } \\
\text { (a) }\end{array}$ & Compound & $\begin{array}{c}\mathrm{d} \text {-spacing, } \\
\mathrm{m}\end{array}$ & $\begin{array}{c}\text { Intensity } \\
\text { (a) }\end{array}$ & Compound \\
\hline $4.72 \times 10^{-10}$ & $\mathbf{M}$ & $\mathrm{Ta}_{6} \mathrm{O}$ or $\mathrm{TaO}_{2}$ & $4.72 \times 10^{-10}$ & $\mathrm{VW}$ & $\mathrm{Ta}_{6} \mathrm{O}$ or $\mathrm{TaO}_{2}$ \\
\hline 3.870 & VW & $\mathrm{Ta}_{2} \mathrm{O}_{5}$ & 3.870 & W & $\mathrm{Ta}_{2} \mathrm{O}_{5}$ \\
\hline 3.600 & VW & $\mathrm{Ta}_{4} \mathrm{O}$ & 3.149 & W & $\mathrm{Ta}_{2} \mathrm{O}_{5}$ \\
\hline 2.722 & vs & $\mathrm{Ta}_{2} \mathrm{O}$ & 2.721 & vs & $\mathrm{Ta}_{2} \mathrm{O}$ \\
\hline 2.579 & VW & $\mathrm{TaO}_{2}$ & 2.600 & W & $\mathrm{TaO}_{2}$ \\
\hline 2.446 & VVW & $\mathrm{Ta}_{2} \mathrm{O}_{5}$ & 2.447 & W & $\mathrm{Ta}_{2} \mathrm{O}_{5}$ \\
\hline 2.395 & $\mathbf{M}$ & $\mathrm{Ta}_{4} \mathrm{O}$ or $\mathrm{Ta}_{6} \mathrm{O}$ & 2.394 & W & $\mathrm{Ta}_{4} \mathrm{O}$ or $\mathrm{Ta}_{6} \mathrm{O}$ \\
\hline 2.354 & $\mathbf{M}$ & $\mathrm{Ta}_{2} \mathrm{O}$ & 2.355 & $\mathbf{M}$ & $\mathrm{Ta}_{2} \mathrm{O}$ \\
\hline 2.327 & $\mathrm{w}$ & $\mathrm{Ta}_{6} \mathrm{O}$ & 2.286 & $\mathrm{~W}$ & $\mathrm{Ta}_{4} \mathrm{O}$ \\
\hline 2.288 & $\mathrm{w}$ & $\mathrm{Ta}_{4} \mathrm{O}$ & 2.111 & W & $\mathrm{Ta}_{2} \mathrm{O}$ \\
\hline 2.110 & VW & $\mathrm{Ta}_{2} \mathrm{O}$ & 1.928 & W & $\mathrm{Ta}_{2} \mathrm{O}$ \\
\hline 1.929 & W & $\mathrm{Ta}_{2} \mathrm{O}$ & 1.795 & $\mathbf{S}$ & $\mathrm{Ta}_{4} \mathrm{O}$ \\
\hline 1.795 & $\mathrm{~S}$ & $\mathrm{Ta}_{4} \mathrm{O}$ & 1.668 & $\mathbf{S}$ & $\mathrm{Ta}_{2} \mathrm{O}$ \\
\hline 1.674 & $\mathrm{~S}$ & $\mathrm{Ta}_{2} \mathrm{O}$ or $\mathrm{Ta}_{6} \mathrm{O}$ & 1.653 & W & $\mathrm{Ta}_{2} \mathrm{O}_{5}$ \\
\hline 1.654 & VW & $\mathrm{Ta}_{2} \mathrm{O}_{5}$ & 1.576 & S Ta & $\mathrm{Ta}_{2} \mathrm{O}_{5}$ \\
\hline 1.574 & $\mathbf{M}$ & $\mathrm{Ta}_{2} \mathrm{O}$ or $\mathrm{Ta}_{2} \mathrm{O}_{5}$ & 1.423 & w & $\mathrm{Ta}_{2} \mathrm{O}$ \\
\hline 1.424 & VW & $\mathrm{Ta}_{2} \mathrm{O}$ & 1.398 & w & $\mathrm{TaO}_{2}$ \\
\hline 1.403 & W & $\mathrm{Ta}_{4} \mathrm{O}$ & 1.366 & w & $\mathrm{TaO}_{2}$ or $\mathrm{Ta}_{6} \mathrm{O}$ \\
\hline 1.364 & W & $\mathrm{Ta}_{6} \mathrm{O}$ or $\mathrm{TaO}_{2}$ & 1.335 & VW & $\mathrm{Ta}_{4} \mathrm{O}$ \\
\hline 1.339 & Vw & $\mathrm{Ta}_{6} \mathrm{O}$ & 1.299 & W & $\mathrm{Ta}_{2} \mathrm{O}_{5}$ \\
\hline 1.058 & VW & $\mathrm{Ta}_{6} \mathrm{O}$ & 1.114 & W & $\mathrm{Ta}_{2} \mathrm{O}$ \\
\hline
\end{tabular}

${ }^{\mathrm{a}}$ Symbols: $\mathbf{M}=$ medium; $\mathrm{S}=$ strong; $\mathrm{V}=$ very; and $\mathrm{W}=$ weak. 
1.19



(a) Cup.

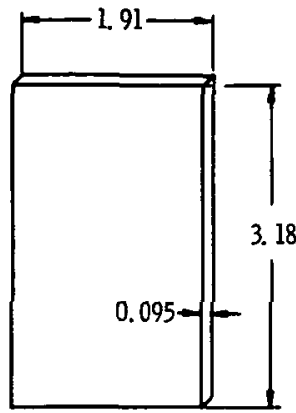

(b) Coupon.

Figure 1. - Dimensions of samples used in this study (all measurements are in $\mathrm{cm}$ ).

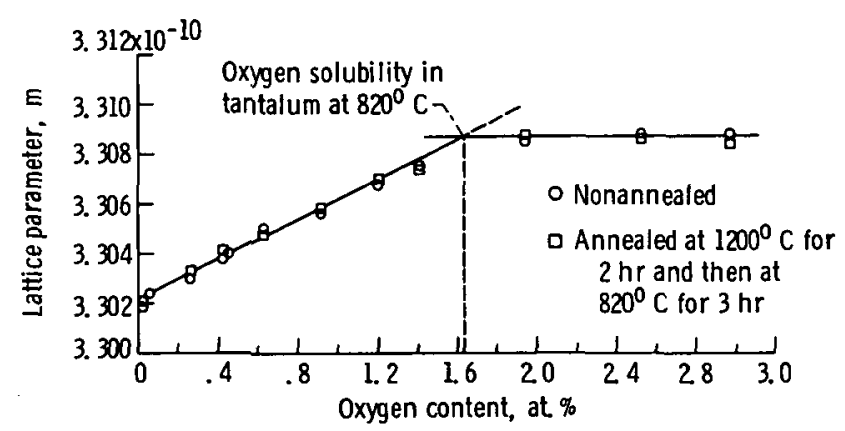

Figure 2 - Tantalum lattice parameter as function of oxygen content. 


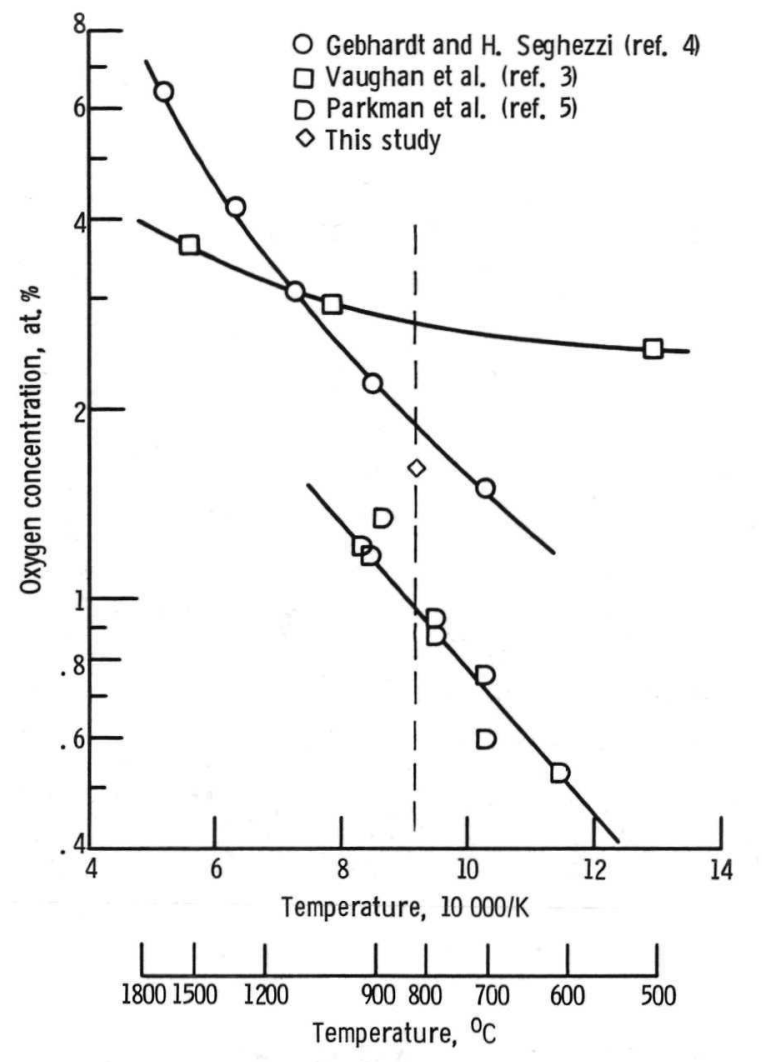

Figure 3. - Solubility of oxygen in tantalum.

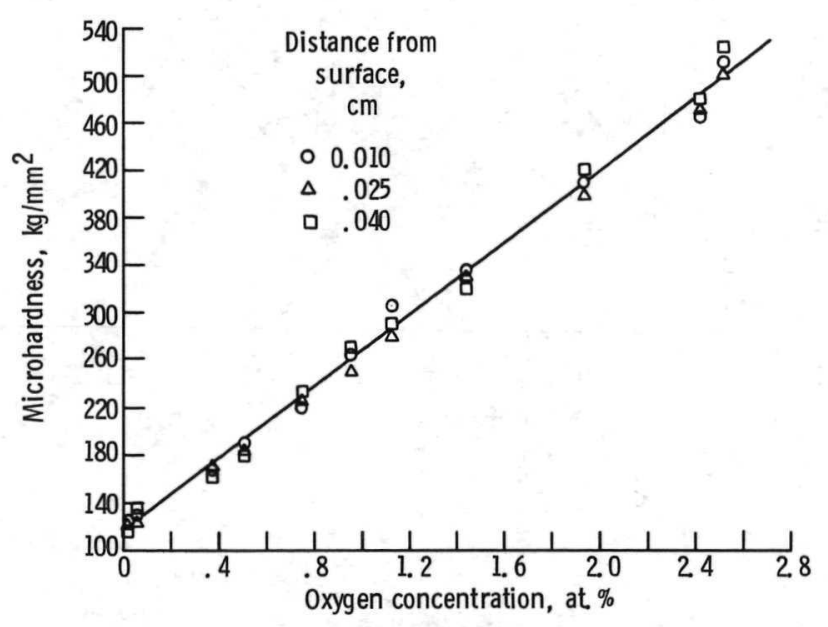

Figure 4. - Cross sectional microhardness of 0.095-centimeterthick, unannealed, oxygen-doped tantalum. 



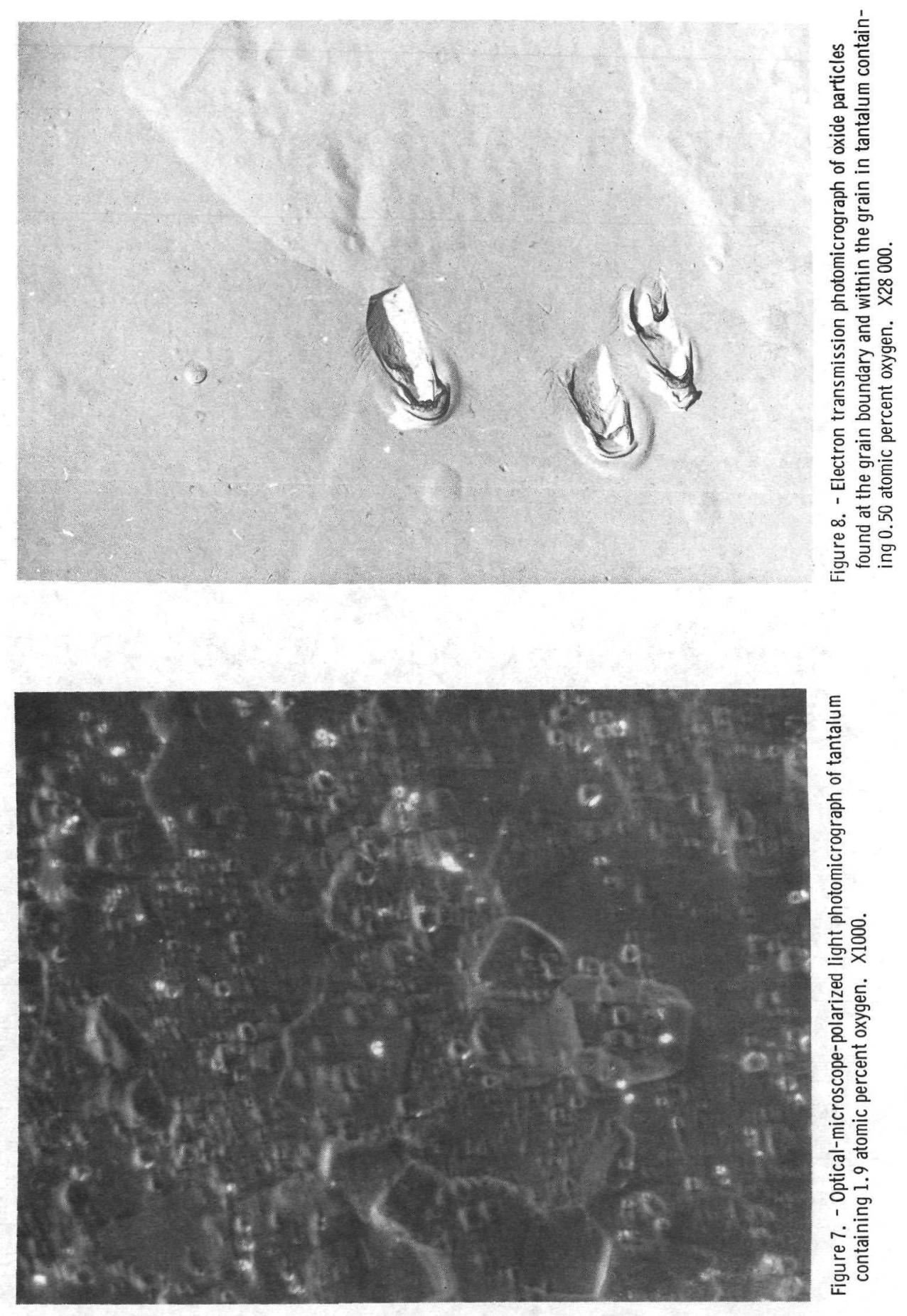

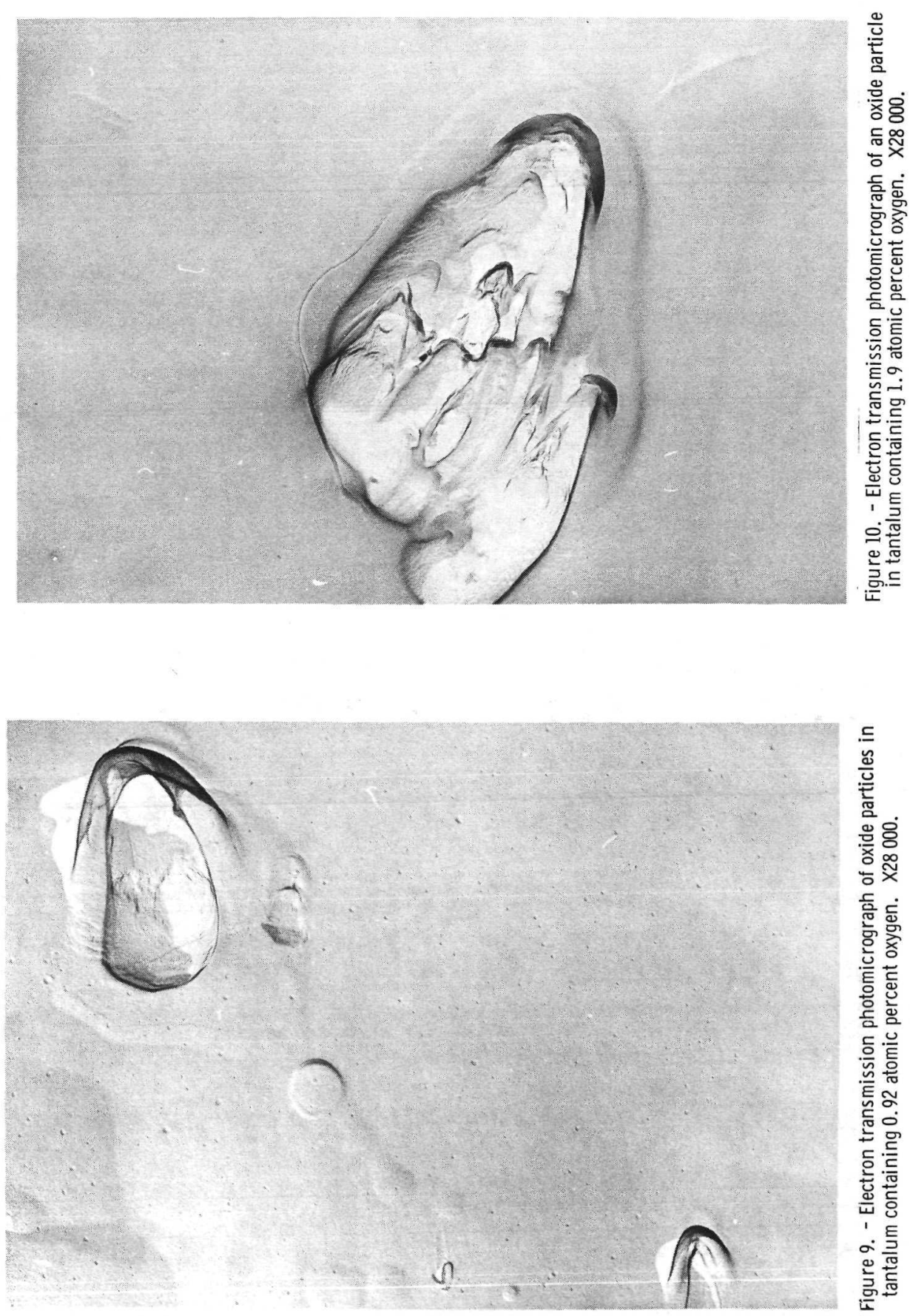
"The deronautical and space activities of the United States shall be conducted so as to contribute . . to the expansion of bruman knowtedge of phenomena in the atmosphere and space. The Administration shall provide for the widest practicable and appropriate dissemination of information concerning its activities and the results thereof."

- Namional Aeronautics and Space Act of 1958

\section{NASA SCIENTIFIC AND TECHNICAL PUBLICATIONS}

TECHNICAL REPORTS: Scientific and technical information considered important, complete, and a lasting contribution to existing knowledge.

TECHNICAL NOTES: Information less broad in scope but nevertheless of importance as a contribution to existing knowledge.

\section{TECHNICAL MEMORANDUMS:}

Information receiving limited distribution because of preliminary data, security classification, or other reasons. Also includes conference proceedings with either limited or unlimited distribution.

CONTRACTOR REPORTS: Scientific and technical information generated under a NASA contract or grant and considered an important contribution to existing knowledge.
TECHNICAL, TRANSLATIONS: Information published in a foreign language considered to merit NASA distribution in English.

SPECIAL PUBLICATIONS: Information derived from or of value to NASA activities. Publications include final reports of major projects, monographs, data compilations, handbooks, sourcebooks, and special bibliographies.

\section{TECHNOLOGY UTILIZATION} PUBLICATIONS: Information on technology used by NASA that may be of particular interest in commercial and other non-aerospace applications. Publications include Tech Briefs, Technology Utilization Reports and Technology Surveys.

Defails on the availability of these publications may be obtained from:

SCIENTIFIC AND TECHNICAL INFORMATION OFFICE 